\title{
O PROFISSIONAL DA INFORMAÇÃO EM ATIVIDADES DE INTELIGÊNCIA COMPETITIVA
}

\author{
EL PROFESIONAL DE LA INFORMACIÓN EN ACTIVIDADES DE \\ INTELIGENCIA COMPETITIVA
}

\author{
Mônica Erichsen Nassif - mnassif@ufmg.br \\ Professora da Escola de Ciência da Informação da UFMG. \\ Doutora em Ciência da Informação
}

Ester Laodicea Santos - esterufmg@yahoo.com.br Bibliotecária. Mestre em Ciência da Informação pela ECI/UFMG

\begin{abstract}
Resumo
Analisou-se a atuação dos profissionais da informação em atividades de inteligência competitiva em instituições públicas e privadas. Foram apresentadas as categorias profissionais consideradas "profissionais da informação", no que diz respeito ao perfil, habilidades e competências. Discorreuse a respeito da evolução da referida atividade, as habilidades e competências do profissional e o papel do profissional da informação em equipes de inteligência competitiva em cada etapa do ciclo. Realizou-se um estudo com onze profissionais que atuam nessa área, com destaque para os profissionais da informação, no sentido de caracterizar a sua atuação em relação às etapas do ciclo de inteligência competitiva e apontar as suas habilidades e competências para atuar em cada fase do ciclo. Concluiu-se que a participação do profissional da informação nessas atividades é importante, uma vez que ele executa tarefas relacionadas a todas as etapas do ciclo, exceto na etapa de análise de informações, cuja atuação foi menos destacada e que suas habilidades e competências estão em consonância com o que preconiza os principais autores apontados na revisão de literatura.
\end{abstract}

\section{Palavras-chave}

Inteligência competitiva. Profissional da informação. Profissional de inteligência competitiva.

\section{INTRODUÇÃO}

Vive-se em um ambiente de profundas mudanças sociais impulsionadas pelas novas tecnologias, pela velocidade das comunicações e pela globalização da economia. As organizações valorizam cada vez mais a informação e o conhecimento, utilizando-os com objetivos estratégicos com vistas a apresentar um diferencial, uma vantagem competitiva ante um mercado bastante concorrido. De acordo com Valentim (2007), a informação e o conhecimento têm papel fundamental em ambientes corporativos, porque todas as atividades desenvolvidas, desde o planejamento até a execução das ações planejadas, assim como o processo decisório, são apoiadas por 
informação e conhecimento.

As tecnologias da informação provocaram também muitas alterações nas profissões e no perfil dos profissionais de diversas áreas do conhecimento. E assim, conforme afirma Rezende (2002, p.120), "cada vez mais as organizações passam a ter em seu quadro de pessoal não apenas especialistas técnicos, mas também especialistas em trabalhar a informação".

Nesse contexto, o profissional da informação-PI pode inserir-se, segundo Faria (2005, p.31), "como ativo e agente criativo, capitalizando sua competência informacional para as estratégias da organização em que atua". Ou seja, cada vez mais as organizações necessitam de profissionais da informação ocupando espaços além dos já tradicionais como arquivos e bibliotecas, mas também no gerenciamento de informações estratégicas para a organização, atuando, por exemplo, em atividades de inteligência competitiva - IC, foco deste trabalho.

Essa atividade, muito discutida pela literatura relacionada à gestão da informação e do conhecimento é definida por Gomes e Braga (2004, p.28), dentre outros autores, como processo ético de identificação, coleta, tratamento, análise e disseminação da informação estratégica para a organização, viabilizando seu uso no processo decisório. Há que se destacar que as atividades de IC, que também recebem outras denominações, tais como inteligência empresarial, monitoração informacional, inteligência de mercado, possuem estreita relação com a estratégia organizacional e com as ações relacionadas ao planejamento estratégico.

Encontram-se na literatura muitos estudos sobre o processo, as ferramentas e a importância da atividade de IC para as organizações, tais como os trabalhos de Gomes e Braga (2004), Miller (2002a), Prescott (2002), Tarapanoff (2001) e Valentim (2007), entre outros. Porém, são poucos os estudos sobre os profissionais, ou seja, sobre as habilidades, as competências, o perfil e a formação dos profissionais que desenvolvem essa atividade nas organizações brasileiras, exceto pelos trabalhos de Marcial (2005), Marcial et al (2002) e Furtado (2003) e pelas pesquisas conduzidas pela Associação Brasileira dos Analistas de Inteligência Competitiva (ABRAIC,2009) ${ }^{1}$. No que se refere a pesquisas sobre a atuação do profissional da informação em atividades de IC, os trabalhos são ainda mais escassos, apesar da importância desse profissional ser destacada por autores como Choo (1999), Gomes e Braga (2004), Santos (1999; 2000) e Valentim (2003a), entre outros.

Procurando contribuir para a pesquisa nessa área, o trabalho propôs-se a analisar a atuação do profissional da informação, em atividades de IC, no que diz respeito às etapas do ciclo de inteligência, descrito na literatura, especificamente proposto por Miller (2002b). Paralelamente, buscou-se verificar se os profissionais da informação possuem as habilidades e competências descritas por Miller (2002c) e Marcial (2005) para atuarem com êxito na área de IC.

\footnotetext{
${ }^{1}$ Disponível em: <http://www.abraic.org.br>. Acesso em: 6 maio 2009.
} 
No período de setembro a outubro de 2003, Marcos Furtado, analista de inteligência competitiva e membro da ABRAIC, realizou uma pesquisa intitulada "Perfil do Profissional de Inteligência Competitiva". A partir dos resultados da pesquisa, verificou-se que $9,6 \%$ dos profissionais eram da área de Biblioteconomia ou Ciência da Informação. A partir desta pesquisa, ficou comprovado que existem profissionais da informação, formados em Biblioteconomia ou com pós-graduação em Ciência da Informação, trabalhando em atividades de IC em instituições públicas e privadas.

No que se refere à classificação de profissionais da informação, neste trabalho adotou-se a classificação de Mueller (2004), que considera profissionais da informação o bibliotecário, o arquivista e os mestres e doutores em Ciência da Informação.

Este estudo se justifica, primeiramente, pela abertura do leque de pesquisas sobre as possibilidades de atuação dos profissionais da informação. Existem estudos abundantes sobre o perfil, espaço de atuação e formação do profissional da informação, mas eles não mencionam as atividades de IC como espaço de atuação para esse profissional. Torna-se necessário investigar como é o trabalho desse profissional em uma atividade de IC, em quais etapas do ciclo ele se destaca, e os prováveis motivos para tal, e quais habilidades e competências esses profissionais possuem que condizem com os atributos apresentados pela literatura sobre o tema.

Esse trabalho pode se tornar um instrumento de uso pelos profissionais da informação no direcionamento de suas carreiras, ampliando suas possibilidades de atuação profissional. E o mais importante: eles poderão detectar lacunas em seu perfil profissional e se aperfeiçoar para atuar nessa área.

Sendo assim, o objetivo geral desse estudo foi analisar a atuação do profissional da informação, tendo-se como eixos os aspectos teóricos que definem o ciclo da inteligência competitiva, bem como os aspectos teóricos que discutem as habilidades, as competências e o perfil desse profissional. Como objetivos específicos: 1) Investigar quais as funções específicas dos profissionais da informação que atuam em atividades IC; 2) Descrever as habilidades, as competências e o perfil dos profissionais da informação, em relação às etapas do ciclo de IC: identificação das necessidades de informação; coleta; análise e disseminação da informação; e 3) Analisar a relação existente entre a teoria e a prática da atuação dos profissionais da informação em atividades de IC, tendo-se como base o ciclo da IC.

\section{O PROFISSIONAL DA INFORMAÇÃO}

Na literatura da área de Ciência da Informação, existem vários estudos sobre a temática profissional da informação e pode-se perceber que apresentar uma definição clara para o termo é algo difícil e complexo, diante da variedade de definições existentes, algumas até contraditórias. Algumas análises são bastante abrangentes e consideram que todo profissional é profissional da 
informação por se utilizar dela em suas atividades. Já outros pontos de vista, como o de Crivellari e Cunha (2004), consideram somente o bibliotecário como um profissional da informação.

Tarapanoff realizou, em 1997, um estudo sobre o perfil do profissional da informação no Brasil. À época, sua pesquisa apurou que a maioria (82,54\%) dos profissionais da informação eram bibliotecários que desenvolviam atividades tradicionais, mas com um crescente envolvimento em novas tecnologias e novos procedimentos administrativos.

Mota e Oliveira (2005, p.99) afirmam que a conceituação de profissional da informação "está em processo evolutivo e sua abrangência ainda se encontra indeterminada, suscitando vários debates em torno de quem realmente pode ser considerado tal".

Para Mueller (2004), parece haver consenso que entre os profissionais da informação incluem-se os bibliotecários, os arquivistas e os mestres e doutores formados nos programas de pós-graduação em Ciência da Informação.

E, por fim, Valentim (2004, p.140) entende por profissional da informação "o indivíduo que recebeu formação específica para trabalhar com dados, informação e conhecimento, bem como sua mediação".

Para o desenvolvimento desta pesquisa, foi escolhido o ponto de vista de Mueller (2004) uma vez que o foco do trabalho é revelar a IC como um espaço de atuação para os profissionais da informação, em que buscar-se-á detectar as atividades que desenvolvem em cada fase do ciclo de inteligência, bem como as habilidades e competências desses profissionais.

No que diz respeito às competências, habilidades e perfis necessários ao profissional da informação para atuar de forma bem-sucedida na atual sociedade da informação, a literatura é rica em apresentar essas características desejáveis (CUNHA, 2000; FARIA 2005; FERREIRA, 2003; MUELLER, 2004; TARAPANOFF, 1997; VALENTIM, 2004; 2002b).

Ressalta-se ainda que perfis e habilidades, tais como domínio de ferramentas de informática, fluência em línguas estrangeiras, criatividade, capacidade de trabalhar em equipes multidisciplinares, dinamismo, ética e investimento em educação continuada são essenciais a todos os profissionais de qualquer área do conhecimento. Porém, tornam-se imprescindíveis aos profissionais da informação, pois a informação, seu objeto de trabalho, é complexa e mutável, principalmente porque depende das necessidades dos indivíduos e das organizações em determinado contexto.

No que se refere às competências, aqui se destacam aquelas citadas por Valentim (2002b). A autora cita as recomendações apontadas pelo Encontro de Diretores de Escolas de Biblioteconomia e Ciência da Informação do Mercosul $^{2}$, que divide as competências para o profissional da informação nas seguintes categorias: competências de comunicação e expressão,

${ }^{2}$ PROGRAMA, Acuerdos y Recomendaciones. In: ENCUENTRO DE DIRECTORES DE ESCUELAS DE BIBLIOTECOLOGÍA Y CIÊNCIA DE LA INFORMACIÓN DEL MERCOSUR, 4, 2000, Montevideo. Anais... Montevideo: EUBCA, 2000. 
competências sociais e políticas, competências gerenciais. Destaca-se que tais competências sintetizam a opinião de outros autores que desenvolvem pesquisas sobre o perfil, as habilidades e competências dos profissionais da informação.

\section{O PROFISSIONAL DE INTELIGÊNCIA COMPETITIVA}

Sabe-se que a IC é um processo que envolve a estratégia da organização, por meio da antecipação de demandas de informação, nos níveis de decisão estratégica e operacional. Além disso, com o aumento da concorrência entre as organizações, muitas delas estão adotando práticas de IC. Por isso, faz-se necessária a participação de profissionais qualificados e competentes para executar as tarefas de coleta, análise e disseminação de informação.

Autores como Miller (2002c), Marcial et al (2003) e Marcial (2005), dentre outros, realizaram estudos em que descrevem habilidades e competências que todo profissional atuante em IC precisa possuir. Vale destacar que a maioria dos autores encontrados na literatura utiliza, com algumas variações, as habilidades e competências de Miller (2002c) relacionadas às fases do ciclo de IC. A literatura traz expressões como "profissional de inteligência", "analista de inteligência", "consultor em inteligência" para designar os profissionais que exercem atividades de IC, como consultores ou como membros do quadro de pessoal da organização.

No Brasil, existem várias pesquisas sobre o tema em programas de Pós-Graduação em Ciência da Informação, como o da Universidade Federal de Minas Gerais (UFMG) e Universidade Federal de Santa Catarina (UFSC), além de pesquisas de outras universidades ligadas aos programas de Administração e Engenharia de Produção. E como já citado, existe também a ABRAIC que oferece cursos de formação e de aperfeiçoamento nessa atividade.

Miller (2002c, p.82) pondera que, embora existam pessoas com instinto natural para as atividades de IC, a experiência e o treinamento, são fatores essenciais para que os profissionais executem as tarefas de forma bem sucedida. Ele completa ainda afirmando que essas habilidades e treinamento podem ser alcançados a partir de programas acadêmicos e apresenta as habilidades e qualificações necessárias ao profissional, de acordo com o ciclo da IC.

Miller (2002a) afirma que na primeira etapa - identificação dos responsáveis pelas principais decisões e suas necessidades em matéria de inteligência - é necessária considerar que as decisões em geral ocorrem em níveis inferiores ao nível executivo. Na maioria dos casos, elas acontecem em nível de chefia direta, por exemplo.

$\mathrm{Na}$ etapa seguinte, a coleta de informação, a equipe obtém os dados relevantes a partir de fontes primárias e secundárias, tendo-se como parâmetro as necessidades informacionais dos principais decisores da organização. Nessa fase, é importante seguir um roteiro para que o pro- 
cesso não perca o rumo. A seguir, os profissionais de IC identificam padrões e tendências significativos e fazem relações e cruzamentos entre as informações obtidas.

A terceira fase do ciclo é feita toda a análise dos dados coletados. Para isso, são utilizadas variáveis estatísticas, variáveis qualitativas e outras técnicas e ferramentas específicas que permitam que a informação resultante responda às necessidades estratégicas dos decisores.

E, por último, a fase de disseminação de informação permite que as análises estejam disponíveis para os decisores, considerando-se o nível de sigilo de cada uma delas, o formato - relatórios, resumos, intranet, reuniões - e a eficácia do conteúdo para subsidiar as atividades organizacionais.

Miller (2002c) faz uma relação entre as etapas do ciclo e as atividades específicas que devem ser desenvolvidas pela equipe de IC. Na primeira etapa do ciclo, ou seja, na identificação dos principais responsáveis pelas decisões e suas necessidades informacionais, o autor destaca que o profissional precisa:

a) saber comunicar-se com os administradores do primeiro escalão;

b) possuir perspicácia para os negócios: o conhecimento do setor e sua terminologia específica capacitarão o profissional a contextualizar a inteligência;

c) avaliar detidamente as estruturas de poder e os processos decisórios da organização.

$\mathrm{Na}$ fase seguinte do ciclo, o momento de coleta de dados requer aptidões diferentes. É importante destacar que, com as múltiplas possibilidades proporcionadas pelas tecnologias de informação, a capacidade de coletar informação tornou-se um desafio muito grande. O profissional necessita:

a) conhecer em profundidade e saber utilizar as fontes de informação escrita, eletrônica e oral;

b) possuir persistência e capacidade de elaborar boas estratégias de busca, principalmente em bancos e bases de dados, além da Internet, pois nesse caso as informações estão menos organizadas;

c) possuir conhecimentos de metodologia científica e pensamento estratégico; e

d) ser capaz de aprender de forma independente com o objetivo de se tornar quase um especialista em um assunto até então desconhecido.

A terceira fase, denominada análise da informação, é a que exige uma combinação rara de habilidades e quase sempre é o maior desafio para o profissional de inteligência, necessitando o profissional:

a) conhecer tudo sobre o setor do qual se está tratando, incluindo as práticas e posições atuais da organização em relação ao assunto abordado; 
b) entender as ferramentas analíticas usadas para formatar a pesquisa; e

c) ter uma ampla compreensão das numerosas e variadas forças que eventualmente possam vir a exercer influência sobre a empresa.

$\mathrm{Na}$ quarta e última etapa do ciclo, que diz respeito à disseminação da informação para os responsáveis pelas decisões, o mesmo autor ressalta que o profissional necessita:

a) usar suas habilidades de pesquisa, criatividade e intuição para reunir impressões e observações originais capazes de facilitar a tarefa dos decisores;

b) compreender as estruturas de poder da organização, a cultura organizacional e as inclinações gerais dos decisores (para os quais o profissional irá encaminhar seu relatório de IC);

c) possuir muita determinação;

d) conhecer a maneira pela qual cada decisor prefere a apresentação da inteligência (relatrio impresso ou eletrônico, forma textual ou gráfica, ou todas as formas acima citadas, de modo resumido).

No que se refere às características pessoais, o autor cita a criatividade, a persistência, a mente analítica, a astúcia para os negócios e a capacidade de aprender independentemente. Sabe-se que a maior parte dessas características são bem-vindas em qualquer profissional. Talvez a mais importante seja a capacidade de aprender sobre um assunto específico e desconhecido de forma independente (MILLER, 2002c).

Miller (2002c, p. 84) recomenda que o profissional faça cursos e treinamentos nas áreas de pensamento estratégico, terminologia de negócios, pesquisa de mercado e técnicas de apresentação. Além disso, é importante conhecer fontes primárias e secundárias de informação e métodos de pesquisa.

E por fim, Miller (2002c) cita os mentores como incentivadores dos profissionais e ajudantes na superação de obstáculos encontrados, principalmente no início da carreira. Além disso, eles podem contribuir para o aperfeiçoamento da capacidade de comunicação e de pesquisa dos profissionais.

\section{O PAPEL DO PROFISSIONAL DA INFORMAÇÃO EM UMA EQUIPE DE IC}

Para Valentim (2003b, p.21), o profissional da informação é fundamental para o êxito do processo de IC em organizações, pois "desenvolve um trabalho voltado ao trinômio dados, informação e conhecimento, com vistas a apoiar as atividades desenvolvidas pela organização".

No contexto da IC, o profissional da informação deve, segundo Valentim (2004), conhecer o setor produtivo, observar as tendências econômicas e mercadológicas de seu país e de outras 
regiões do mundo, bem como avaliar constantemente sua competência, potencialidade e conhecimentos sobre a cadeia de produção em que atua. Além disso, o profissional da informação precisa conhecer profundamente os métodos, as técnicas e os instrumentos existentes para as atividades de IC.

Para Santos (1999/2000, p.499), o profissional da informação é importante em um sistema de IC, "pois possui habilidades para identificar e explorar tipos variados de fontes de informação, independentemente do seu grau de estruturação". Na verdade, o profissional da informação possui formação, competências e habilidades para gerenciar fluxos de informação, seja qual for a organização ou o perfil do usuário/cliente em questão.

\section{METODOLOGIA}

O estudo foi de natureza exploratória, visando a conhecer melhor a atuação dos profissionais da informação - bibliotecários, arquivistas e pós-graduados em ciência da informação, conforme Mueller (2004) - em atividades de IC. Aqueles profissionais com outras formações e que não possuíam mestrado ou doutorado na área de Ciência da Informação foram denominados outros profissionais.

Tratou-se de uma pesquisa qualitativa e, desta forma, para a coleta de dados, utilizou-se um roteiro de entrevista, ou seja, o instrumento de coleta de dados foi a entrevista. Tal método é também denominado entrevista padronizada ou estruturada, pois de acordo com Marconi e Lakatos (2006, p. 199), "o entrevistador segue um roteiro previamente estabelecido, e as perguntas feitas ao indivíduo são pré-determinadas".

A pesquisa foi realizada com profissionais que atuam em atividades de IC em instituições públicas e privadas e que aceitaram participar do estudo tais como Sebrae, Petrobrás, Vale, Correios, Polícia Federal, Tw Service; Fundação Bio Rio e Roche. Os critérios para a escolha da amostra foram a indicação das organizações ao Prêmio Abraic de $2008^{3}$ e o conhecimento prévio da pesquisadora sobre a existência de setores de IC em algumas organizações.

Foram realizados 17 contatos e entrevistados 11 profissionais no período de fevereiro a março de 2009. Algumas entrevistas foram presenciais e outras por telefone, mas todas foram gravadas. A escolha dos profissionais deu-se por se ter conhecimento da existência de atividades de inteligência competitiva nessas e em outras organizações do país e, após contatos estabelecidos, esses profissionais se dispuseram a participar da pesquisa.

Alguns profissionais, a pesquisadora já conhecia e isto facilitou o acesso a eles. Nesse caso, foi enviado um e-mail contendo os objetivos da pesquisa e o convite para participação da

\footnotetext{
${ }^{3}$ Trata-se de um instrumento criado para honrar, reconhecer e celebrar projetos de inteligência competitiva que demonstraram as verdadeiras e melhores práticas no País.
} 
mesma diretamente para o e-mail do profissional. Além disso, estes profissionais já conhecidos puderam indicar outros que também desenvolviam atividades de inteligência em suas organizações ou em outras. É o que se chama amostra "bola de neve", pois envolve pedir às pessoas participantes de uma pesquisa para nomear outras pessoas que estariam dispostas a participar. Sendo assim, os dados foram obtidos junto a estes profissionais, que, independentemente do cargo que ocupavam na instituição, tivessem em comum o fato de atuarem em atividades de IC.

O roteiro de perguntas foi estruturado em três conjuntos de questões. O primeiro conjunto dizia respeito aos aspectos pessoais do profissional entrevistado, tais como sexo, idade, nível educacional, área de formação superior, se possuía ou não formação específica em IC, tempo de atuação na área, se havia realizado treinamentos de apoio na área e estado brasileiro onde estava localizada a instituição em que o profissional desenvolvia a atividade de IC.

O segundo conjunto constituía-se de questões referentes à atividade de IC. Sendo assim, cada profissional respondeu a perguntas sobre a atividade de IC que desenvolvia, considerando o ciclo de inteligência; se exercia outra atividade além daquela; as fontes de informação mais utilizadas; os métodos e ferramentas de análise de informação; quais ferramentas tecnológicas utilizavam na atividade; se havia estudado sobre o setor de atuação da organização para conhecer a terminologia da área, as estruturas de poder e a cultura da instituição; como era a comunicação com o primeiro escalão da organização; que aspectos consideravam importantes para identificar as necessidades exatas de informação dos decisores; se conhecia a forma preferida de entrega da inteligência aos decisores; se costumava descrever hipóteses e formular perguntas durante a atividade; se possuía conhecimentos de segurança de informação e contra-inteligência, metodologia científica e pensamento estratégico; de que forma lidava com as questões éticas da atividade de IC e que características pessoais do profissional eram consideradas importantes para o bom desempenho da atividade de inteligência, além das citadas na própria questão.

E o terceiro e último conjunto foi estruturado por questões sobre a organização na qual a atividade de IC é desenvolvida. Perguntou-se aos profissionais em que departamento da organização estava localizada a atividade de IC; qual era o setor econômico e o ramo de atividade da organização; quantos funcionários possuía a organização; há quanto tempo havia sido implementada a atividade de IC na organização; e quantas pessoas eram alocadas para trabalhar nessa atividade.

O entrevistado teve também um espaço para relatar outros aspectos que julgava relevantes sobre a sua atuação em atividades de IC na última questão da entrevista.

Os dados foram agrupados em 3 categorias:

1. apresentação dos entrevistados: questões referentes aos dados pessoais e organizacionais; 
2. ciclo de IC: questões referentes às etapas do ciclo: identificação das necessidades de informação, coleta, análise e disseminação de informação; e

3. habilidades e competências profissionais: questões referentes às habilidades e competências necessárias ao profissional para atuar em atividades de IC.

\section{APRESENTAÇÃO E ANÁLISE DOS DADOS}

Os dados pessoais e organizacionais foram analisados no sentido de apresentar os entrevistados e a organização na qual desenvolviam as atividades de IC. Os dados profissionais foram analisados segundo dois aspectos: o primeiro do ciclo de IC, cujo foco de análise foi verificar se o profissional era ou não profissional da informação e as atividades que ele desenvolvia no ciclo de IC; segundo aspecto das competências e habilidades necessárias ao profissional da informação para desenvolver atividades de IC, cujo objetivo foi verificar se tais habilidades e competências estavam de acordo com o que a literatura prevê para o profissional.

Foram entrevistados 11 profissionais atuantes em atividades de IC, cujas características são:

a) Profissional A - Graduada e mestre em Economia, especialista em Gestão Estratégica da Informação. Atua desde 2008 na área de IC, em uma organização do setor público, do ramo de atividade consultoria na área de educação e de apoio à pequena empresa, localizada no estado de Minas Gerais. Na organização, a profissional é responsável pelo gerenciamento da atividade de IC;

b) Profissional B - Bibliotecário, especialista em Banco de Dados e Inteligência Competitiva e mestrando em Ciência da Informação. Desde 2003 atua na área de IC em uma organização do setor público do ramo de atividade segurança, atuante em todo o Brasil e com filial em Minas Gerais. Pelos critérios do estudo é um profissional da informação;

c) Profissional C - Bibliotecária e especialista em Gestão Estratégica da Informação. TrabaIha desde 2008 na área de IC em uma organização do setor público, do ramo de atividade consultoria na área de educação e de apoio à pequena empresa, localizada em Minas Gerais. A profissional da informação desenvolve atividades tanto do setor de documentação da organização como atividades específicas de IC;

d) Profissional D - Graduada em Geologia e especialista em Geoprocessamento. Trabalha desde 2007 na área de IC em uma organização do setor de indústria de prospecção, transporte e beneficiamento de minérios, cujo ramo de atividade é a mineração e está localizada no estado de Minas Gerais. Desenvolve somente tarefas relacionadas à atividade de IC;

e) Profissional E - Bibliotecária e especialista em Organização da Informação em Contextos 
Digitais. Atua desde 2006 na área de IC em uma organização do setor de indústria de prospecção, transporte e beneficiamento de minérios, cujo ramo de atividade é a mineração e está localizada em Minas Gerais. A profissional da informação desenvolve tanto atividades do setor de documentação e informação da empresa, como também as atividades do setor de IC;

f) Profissional F - Graduada em Farmácia Industrial, possui MBA em Gestão do Conhecimento e Inteligência Empresarial. Desde o ano de 2007 atua na área de IC em uma organização do setor de indústria química e biotecnologia, cujo ramo de atividade são fármacos e cosméticos, localizada no estado do Rio de Janeiro. Executa tarefas estritamente ligadas ao setor de IC;

g) Profissional G - Bibliotecária, possui MBA em Gestão de Negócios e Inteligência Competitiva. Atua desde o final do ano de 2007 na área de IC em uma organização do setor de indústria de exploração e refino de petróleo e seus subprodutos, cujo ramo de atividade é a energia e está localizada no estado do Rio de Janeiro. Desenvolve atividades de IC em tempo integral;

h) Profissional H - Graduado em Administração e especialista em Recursos Humanos. Atua desde 2003 na área de IC em uma organização do setor econômico da indústria química, cujo ramo de atividade é o farmacêutico e está localizada no estado de São Paulo. Desenvolve atividades relacionadas somente ao setor de IC;

i) Profissional I - Bibliotecária e possui MBA em Gestão de Negócios e Inteligência Competitiva. Atua desde 2005 em atividades de IC em uma organização do setor de indústria de exploração e refino de petróleo e seus subprodutos, cujo ramo de atividade é a energia e está localizada no estado do Rio de Janeiro. Trata-se de um profissional da informação, pelos critérios dessa pesquisa, que não desenvolve outras tarefas além daquelas relacionadas à área de IC;

j) Profissional J - Graduado em Engenharia Elétrica e mestre em Tecnologia da Informação. Atua desde 2003 na área de IC em uma organização do setor de indústria de telecomunicações e componentes eletrônicos, cujo ramo de atividade é telecomunicações e computação e está localizada em São Paulo. Desenvolve tanto atividades relacionadas à sua formação, como atividades do setor de IC;

k) Profissional K - Graduado em Administração e Direito e possui MBA em Inteligência Competitiva, Práticas e Ferramentas, com ênfase em Business Intelligence. Desde fevereiro de 2006 atua na área de inteligência competitiva em uma organização do setor público, cujo ramo de atividade é comunicação e logística e está localizada no Distrito Federal. Executa somente atividades relacionadas ao departamento de IC.

O estudo demonstrou que os profissionais exercem tanto as atividades específicas do se- 
tor de IC da organização, como também aquelas relacionadas ao setor de informação da organização. Entre os entrevistados, há profissionais que trabalham na área de IC em um projeto sobre a memória da organização. Alguns profissionais da informação atuam em todas as etapas do ciclo de inteligência, já outros atuam com destaque em uma etapa específica.

A pesquisa revelou que todos os profissionais da informação participam ativamente da etapa de coleta de informação, demonstrando preocupação em relacionar a fonte de informação com o perfil de quem está precisando dela. De maneira geral, os profissionais da informação fazem uso de tipologias variadas de fontes de informação especificadas na literatura, tais como pessoas, bases de dados, Internet, intranet, bibliotecas digitais, dentre outras.

Observou-se que os profissionais da informação atuam com destaque também nas etapas de identificação de necessidades de informação e de disseminação de informação. Os profissionais da informação entrevistados ressaltaram que as necessidades de informação dos decisores são identificadas por meio de entrevistas e questionários. Além disso, eles disseminam a informação procurando conhecer a forma preferida da apresentação da informação pelo decisor no momento de fornecerem os produtos de inteligência. Os principais formatos de apresentação citados foram relatórios, e-mails, apresentações em power point e pessoalmente.

É especialmente importante ressaltar que os dados demonstraram que o profissional da informação praticamente não atua na etapa de análise de informações. A etapa de análise exige um conhecimento profundo tanto do setor de atuação da organização como das técnicas de análise. Somente dois profissionais da informação responderam não possuir capacidade para realizar análise de informação, encaminhando as informações para serem analisadas pelo especialista no negócio da organização. Os autores pesquisados destacam que esta é a etapa mais complexa do ciclo de IC.

Apesar de autores como Santos (1999/2000) destacarem que ele pode atuar em todo o ciclo, a pesquisa mostrou que na prática isto não ocorre. Mas, uma vez que a atividade é realizada em equipe, com a contribuição de profissionais provenientes de várias áreas do conhecimento, o profissional da informação dá a sua contribuição nas outras etapas, como demonstrou a pesquisa. Portanto, a pesquisa confirma que o profissional da informação precisa trabalhar junto ao especialista do negócio da organização, precisa de tempo e treinamentos para conhecer bem a terminologia do setor e a própria organização na qual atua.

Sobre as habilidades e competências necessárias ao profissional de inteligência, percebeu-se que, de maneira geral, os profissionais da informação as possuem, dependendo do contexto da organização e da real necessidade de tal habilidade/competência no desenvolvimento de suas tarefas. Verificou-se que habilidades e competências para atuar em inteligência competitiva estão em consonância com o que preconizam os teóricos Miller (2002c) e Marcial (2005), citados no decorrer do trabalho. As habilidades e competências do profissional da informação foram dis- 
cutidas de uma maneira ampla e observou-se que a literatura relaciona as habilidades aos contextos convencionais de atuação profissional. Já no que se refere aos profissionais de inteligência competitiva, observou-se que os autores ampliam mais o leque de atuação e citam todas as fases do ciclo de inteligência como possibilidades para o profissional da informação atuar.

Sobre a conduta ética no exercício das atividades de inteligência competitiva, todos os profissionais da informação responderam possuir conhecimentos sobre o tema e cumprir as normas éticas exigidas pela organização em que atuam em todas as etapas do ciclo de IC.

Observou-se também a preocupação dos profissionais da informação em estarem sempre se atualizando sobre os temas da área. Eles buscam a capacitação na área de IC por meio de cursos de especialização, em eventos da área e também em treinamentos e cursos de curta duração.

Outro aspecto que é importante de ser destacado, através dos dados das entrevistas, é que um dos maiores desafios tanto para os profissionais da informação quanto para os outros profissionais diz respeito aos aspectos cultuais e comportamentais das organizações. Para eles, é necessário convencer as pessoas sobre a importância e os objetivos da atividade de IC para a organização e convencê-los a serem fornecedores e usuários da informação.

\section{CONSIDERAÇÕES FINAIS}

Diante do exposto, é importante destacar que em uma atividade de IC dentre os vários profissionais capacitados para efetuar as tarefas está o profissional da informação, por suas características como o profundo conhecimento das mais variadas tipologias de fontes de informação, sua capacidade de síntese de informações, sua capacidade de formular estratégias eficazes de busca de informações e elaboração de produtos de informação.

Aos poucos, com a percepção de algumas organizações para a importância do trabalho do profissional da informação no gerenciamento de informações para a tomada de decisão, têm sido ampliadas as possibilidades de atuação profissional. A sua participação em equipes de IC é apenas uma das comprovações disso.

Os objetivos da pesquisa foram atingidos, pois foi possível analisar a atuação do profissional da informação em atividades de IC, com destaque para a sua atuação mais acentuada na etapa de coleta de informações e pela menor participação na etapa de análise de informações. Além disso, comprovou-se que suas habilidades e competências estão em consonância com os autores pesquisados e que os profissionais buscam aprimorar aquelas que ainda não possuem. $O$ maior desafio apontado pelos próprios profissionais da informação é convencer as pessoas da importância de se institucionalizar as atividades de IC nas organizações.

Fica a certeza de que o profissional da informação, embora tradicionalmente relacionado a 
bibliotecas e arquivos e a materiais impressos, é perfeitamente capaz de atuar em atividades de IC e oferecer sua valiosa contribuição em uma equipe que desenvolva essa atividade. $O$ estudo contribuiu para reafirmar a IC como espaço de atuação efetiva do profissional da informação e que deve ser ocupado com determinação e competência.

Novos estudos que investiguem a atuação do profissional em atividades de IC são necessários. É preciso que se façam pesquisas junto aos profissionais cadastrados na ABRAIC, pois a instituição é a maior força representativa dos profissionais no Brasil.

Outra sugestão para trabalhos futuros é a investigação sobre a participação do arquivista, como profissional da informação que é, em atividades de IC. Nesta pesquisa, não se verificou a participação de nenhum profissional da área de Arquivologia e nem os arquivos foram citados nas etapas do ciclo. É preciso que se estude, em profundidade, os motivos pelos quais os documentos do arquivo das instituições não são utilizados no processo de IC.

É necessário também que se façam pesquisas buscando caracterizar a formação e o perfil dos pós-graduados em Ciência da Informação e dos graduados em Arquivologia, uma vez que são profissionais da informação e a maior parte dos estudos diz respeito ao perfil e área de atuação dos bibliotecários.

E a última sugestão de trabalho futuro é a realização de uma análise comparativa entre os profissionais de IC atuantes em organizações do setor público e do setor privado buscando identificar, dentre outros aspectos, habilidades e competências em cada etapa do ciclo de inteligência; fontes e técnicas de análise de informação utilizadas e os aspectos éticos e comportamentais envolvidos nessa atividade.

\section{REFERÊNCIAS}

ASSOCIAÇÃO BRASILEIRA DOS ANALISTAS DE INTELIGÊNCIA COMPETITIVA- ABRAIC. Disponível em: <http://www.abraic.org.br>. Acesso em: 6 maio 2009.

$\mathrm{CHOO}, \mathrm{C} . \mathrm{W}$. Information management for the intelligent organization: the art of scanning the environment. $2^{\text {nd }}$. ed. Medford: Information Today, 1999. 272p.

CRIVELLARI, H. M.; CUNHA, M. V. Os bibliotecários como profissionais da informação: estratégias e paradoxos de um grupo profissional. In: ENCONTRO ANUAL DA ANPOCS, 28., 2004, Caxambu, Anais... Caxambu: ANPOCS, 2004. p. 1-25.

CUNHA, M. V. Perfil do profissional da informação frente às novas tecnologias. Revista ACB: Biblioteconomia em Santa Catarina, v. 5, n. 5, p. 185-195, 2000.

FARIA, S. et al. Competências do profissional da informação: uma reflexão a partir da Classificação Brasileira de Ocupações. Ciência da Informação, Brasília,v. 34, n. 2, p. 26-33, maio/ago. 2005.

FERREIRA, D. T. Profissional da informação: perfil de habilidades demandadas pelo mercado de trabalho. Ciência da Informação, Brasília, v. 32, n. 1, p. 42-49, jan./abr. 2003 
FURTADO, M. Perfil do profissional de inteligência competitiva. 2003. Disponível em <http://www.abraic.org.br>. Acesso em: 20 nov. 2008.

GOMES, E.; BRAGA, F. Inteligência competitiva: como transformar informação em um negócio lucrativo. 2. ed. Rio de Janeiro: Elsevier, 2004. 139p.

MARCIAL, E. O perfil do profissional de inteligência competitiva e o futuro dessa atividade no Brasil. In: STAREC, C. et al (Orgs.). Gestão estratégica da informação e inteligência competitiva. São Paulo: Saraiva, 2005. cap. 16, p. 242-254.

MARCIAL, E.; COSTA, A. J. L.; CURVELLO, J. J. A. Lícito versus ético: como as ferramentas de inteligência competitiva podem contribuir para a boa imagem corporativa. Revista Inteligência Empresarial, n. 12, p. 23-29, jul. 2002.

MARCIAL, E.; CARVALHO, M. F.; COSTA, A. J. L. Good work turbulent times: the competitive intelligence professional in Brazil. In: BALAS-BUSINESS ASSOCIATION OF LATIN AMÉRICA, 2003, São Paulo. Anais... São Paulo: [s.n], 2003.

MARCONI, M. A.; LAKATOS, E. M. Técnicas de pesquisa: planejamento e execução de pesquisas, amostragens e técnicas de pesquisa, elaboração, análise e interpretação de dados. 3. ed. São Paulo: Atlas, 2006. 231p.

MILLER, J. P. O processo de inteligência: como funciona, seus benefícios e sua situação atual. In: . O milênio da inteligência competitiva. Porto Alegre: Bookman, 2002a. cap.1, p. 32-52.

. O nascimento e o crescimento do seu processo de inteligência: fatores comportamentais, culturais e estruturais. In: 2002b. cap. 2, p. 54-65. O milênio da inteligência competitiva. Porto Alegre: Bookman,

. Qualificações e treinamento para a inteligência. In: competitiva. Porto Alegre: Bookman, 2002c. cap. 4, p. 79-92. . O milênio da inteligência

MOTA, F. R. L.; OLIVEIRA, M. Formação e atuação profissional. In: OLIVEIRA, M. (Coord.) Ciência da informação e biblioteconomia: novos conteúdos e espaços de atuação. Belo Horizonte: Ed. UFMG, 2005. cap. 5, p. 97-109.

MUELLER, S. P. M. Uma profissão em evolução: profissionais da informação no Brasil sob a ótica de Abbot- proposta de estudo. In: BAPTISTA, S. G.; MUELLER, S. P. M. (Orgs.). Profissional da informação: o espaço de trabalho. Brasília: Thesaurus, 2004. cap. 1, p. 23-54. (Estudos Avançados em Ciência da Informação, v.3).

PRESCOTT, J. E. Inteligência competitiva: lições das trincheiras. In: PRESCOTT, J. E.; MILLER, S. H. Inteligência competitiva na prática. Rio de Janeiro: Campus, 2002. cap. 1, p. 11-38.

PROGRAMA, Acuerdos y Recomendaciones. In: ENCUENTRO DE DIRECTORES DE ESCUELAS DE BIBLIOTECOLOGÍA Y CIÊNCIA DE LA INFORMACIÓN DEL MERCOSUR, 4, 2000, Montevideo. Anais... Montevideo: EUBCA, 2000.

REZENDE, Y. Informação para negócios: os novos agentes do conhecimento e a gestão do capital intelectual. Ciência da Informação, Brasília, v. 31, n. 2, p. 120-128, maio/ago. 2002.

SANTOS, R. N. M. Processos, métodos e ferramentas de inteligência organizacional no contexto da sociedade da informação. Revista de Biblioteconomia de Brasília, Brasília, v. 23-24, n. 4, p. 493-508, especial 1999/2000.

TARAPANOFF, K. (Org.) Inteligência organizacional e competitiva. Brasília: UNB, 2001. 343p. 
TARAPANOFF, K. (Org.) Perfil do profissional da informação no Brasil. Brasília: IEL/DF, 1997. $134 p$.

VALENTIM, M. L. P. Inteligência competitiva em organizações: dado, informação e conhecimento. DataGramaZero: Revista de Ciência da Informação, v. 4, n .3, p. 1-13, jun. 2003a. Disponível em: <http://www.dgz.org.br>. Acesso em: 10 set. 2008.

VALENTIM, M. L. P.; ZWARETCH, N. S. Comunicação organizacional/comunicação informacional no processo de inteligência competitiva organizacional. In: VALENTIM, M. L. P. (Org.).

Informação, conhecimento e inteligência organizacional. 2. ed. Marília: FUNDEPE, 2007. cap. 3, p. 45-60.

. et al. O processo de inteligência competitiva em organizações. DataGramaZero - Revista

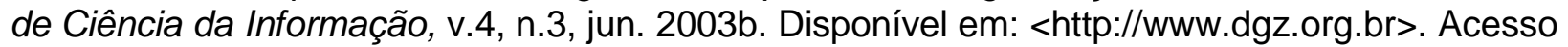
em: 15 maio 2008.

Equipes multidisciplinares na gestão da informação e conhecimento. In: BAPTISTA, S. G.; MUELLER, S. P. M. (Orgs.). Profissional da informação: o espaço de trabalho. Brasília: Thesaurus, 2004. cap. 7, p. 154-176.

Formação: competências e habilidades do profissional da informação. In: (Org.). Formação do profissional da informação. São Paulo: Polis, 2002b. cap. 6, p.117-132.

\title{
Title
}

The information professional in competitive intelligence activities

\begin{abstract}
The role of information professionals in competitive intelligence activities in public and private institutions was analyzed. It presents the professional categories considered as "information professionals" related to profile, skills and abilities. The evolution of competitive intelligence as an activity, the professionals' skills and expertise as well their role in intelligence teams and cycle stages were addressed. A study involving eleven competitive intelligence professionals was conducted, with emphasis on information professionals, in order to characterize their performance concerning competitive intelligence cycle stages and also to point out their abilities and skills to perform in each of the cycle's phases. The study concluded that the information professional participation in competitive intelligence activities is important, as this professional performs tasks related to all cycle's stages, except for the information analysis stage, in which the performance was observed as less prominent. The study results also reinforced that professionals' abilities and skills are in accordance with the main reviewed authors.
\end{abstract}

\section{Keywords}

Competitive intelligence. Information Professional. Competitive intelligence professional.

\section{Título}

El profesional de la información en actividades de inteligencia competitiva

\section{Resumen}

Se analizó el papel de los profesionales de la información en las actividades de la inteligencia competitiva en las instituciones públicas y privadas. Las categorías profesionales se presentaron como "profesionales de la información", en relación con el perfil, las habilidades y competencias. 
Se trata de la evolución de la actividad de inteligencia competitiva, las habilidades y competencias profesionales y el papel de los profesionales de la información en los equipos de inteligencia competitiva y en cada etapa del ciclo de la inteligencia competitiva. Se realizó un estudio con once profesionales que trabajan en esta área, con énfasis en los profesionales de la información con el fin de caracterizar su desempeño en relación con las etapas del ciclo de la inteligencia competitiva y mostrar sus habilidades y destrezas para llevar a cabo en cada fase del ciclo. Se concluyó que la participación de profesionales de la información en estas actividades es importante, ya que realiza tareas relacionadas con todas las etapas del ciclo, excepto en la fase de análisis de información, cuyo desempeño fue menos importante y que sus habilidades y competencias están en línea con los llamamientos que se identificaron los principales autores de la revisión de la literatura.

\section{Palabras clave}

Inteligencia competitiva. Profesional de la información. Profesional de inteligencia competitiva.

Recebido em: 22.06.2009

Aceito em: 03.11.2009 